\title{
Beaded Kente Ladies Shoe (Stilettos) for Contemporary Ghanaian Traditional Weddings
}

\author{
${ }^{1}$ Frederick Ampah Clement, ${ }^{2}$ Kafui Kwesi Agyeman $(\mathrm{PhD}),{ }^{3}$ Eugene Padditey and ${ }^{4}$ Harold Awuley Quaye \\ 1, 2, 3,4 Department of Integrated Rural Art and Industry, Faculty of Art, Kwame Nkrumah University of Science and Technology, \\ Kumasi, Ghana
}

\begin{abstract}
This paper focuses on the creation of a beaded kente ladies shoe (stilettos - women's shoe with a long heel) for contemporary Ghanaian traditional weddings. The research sought to identify some of the types of footwear brides use for traditional weddings, and improve the design through the integration of beads and kente. Research questions posed were as follows: 1 . What are some of the footwear used by brides for traditional weddings? 2. How can the design of one of the shoe types be improved with the integration of beads and kente? The descriptive research method was used to give details on the tools and materials used for the footwear, types of beads and kente, and the processes for making the ladies footwear for traditional weddings in Ghana. The participatory product design method was used, where the would-be users of the footwear were involved in the design process. The population for the study was 150 residents of Manhyia, a suburb of Kumasi. It was realised that, in terms of footwear for traditional weddings, the preference today's woman has is for the flat or the stiletto kind. The target price, target users and product features were established based on which intended designs/sketches were made. The creation stage saw the use of six (6) operations: pattern cutting, closing, lasting, attaching, arrangement of beads, and finishing. Techniques employed were user friendly and can be practiced by many a person.
\end{abstract}

Keywords:- Beads, kente, stilettos, Ghanaian, weddings.

\section{INTRODUCTION}

The variety of ladies wedding footwear for traditional weddings in Ghana can be increased with the application and integration of indigenous items such as beads and kente. The creativity of the Ghanaian footwear maker can be taken a notch higher in this regard. A benefit of this is that Ghanaian culture will be further promoted. The manufacture and consumption of such footwear, by the youth, will positively help to reduce the high unemployment rate in the country.

An individual is ready to marry only after the performance of the necessary initiation rites. A cardinal reason for marriage is bearing children; and is stressed throughout the initiation rites. (GhanaNation Portal, 2010). In the traditional set-up, marriage involves the man and the woman concerned as well as their families. Before the marriage, most families try to investigate each other's background to ensure that nothing prevents a successful marriage. (GhanaNation portal, 2010). The investigations usually seek answers to questions on health, hereditary and behaviour of the persons involved.

Many Ghanaian traditional weddings showcase the use of indigenous accessories and materials in various ways, for example, the bead. According to TheFreeDictionary (2013), a bead is a small, often round piece of material, such as glass, plastic, or wood that is pierced for stringing or threading. Beads is a necklace, wrist bands, and the like, made of such pieces. The modern appreciation of beads is influenced by age and academic status though the use of beads in ceremonies has remained relatively constant throughout the ages (Ashe, 2012). Political, economic and religious persuasions have made bead use what it is today. Beads are a symbol of cultural and financial wealth and are sometimes used to communicate intent concerning marriage. Because adornment is often linked to romance, beads play a significant role in attracting members of the opposite sex they are valuable in attracting a mate. In Ghana, a young girl from the Krobo region wears pounds of ancestral beads designed to show her family's wealth (Travel Africa Magazine, 1999). Also, some young men create beads from bamboo and give them to girls they like. If the girl likes the boy she will wear his beads. These facts about the use of beads make them ideal for enhancing the design of a stiletto for Ghanaian traditional weddings.

"Kente" is a brilliantly colourful fabric (cotton, rayon, sheen, and the like), entirely or solely hand-woven on a horizontal treadle loom by the Asantes and Ewes in Ghana. The colours and designs of the kente have made the fabric the best known of all Ghanaian and most of African textiles. Each design or cloth has a story with a proverbial meaning with its own distinction. (AsanteMan Kente Works, 2013). Each of the colours of the Kente has relevance for usage. Few examples are yellow, our gold or wealth; violet, the royalty of our culture; pink, gentleness, calmness, sweetness, and tenderness of the Ghanaian; and red, blood relationship and strong political and spiritual feelings. From this, it can be deduced that kente for a bride during a wedding communicates how marriage is good, honourable, sweet and leads to strong inter-family ties. This attests to why the use of kente has been consistent and preferable in Ghanaian wedding ceremonies.

This study sought to identify some of the footwear brides use for traditional weddings, and improve the design of one of the footwear (shoe) through the integration of beads and kente. Research questions posed were as follows: What are some of the footwear used by brides for Ghanaian 
traditional weddings? How can the design of one of the shoe types be improved with the integration of beads and kente?

\section{MATERIALS AND METHODS}

\section{A. Materials}

Key materials used for the footwear were Asante kente (in the babadua and edwini fashion), glass beads, leather, and plastic. The babadua kente (Kente Cloth.net, 2010) that was used had green and light yellow as its colours (Fig. 1), though the babadua can be in other colours such as in Fig. 2. Edwini, on the other hand, means intricacy of design (Sabutey, 2009) that is integrated with the plain weave in any kente cloth woven on the Asante traditional loom. The edwini (Fig. 3) employed in the stilettos is an example of a recent style. An example of the traditional edwini is the rising sun (awia repue) design (Fig. 4).

The study employed glass beads of two kinds; the first is small and rounded in nature, and the other also rounded but relatively larger and ellipsoid in nature with a frosty look; the frosty appearance emanates from its angular surfaces.

The addition of glass beads and kente fabric helped to improve the appeal for traditional weddings. The kente fabric is durable and well accepted for ceremonial occasions.

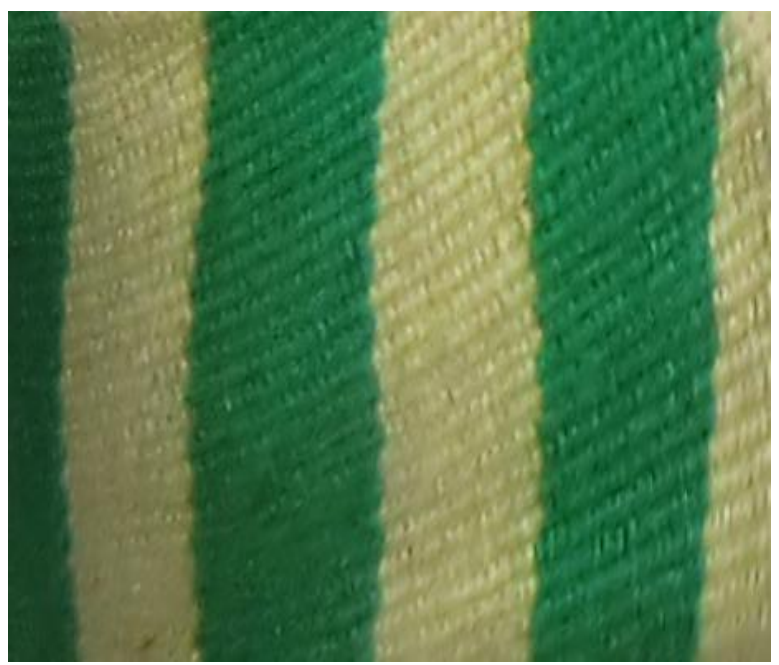

Fig 1:- Babadua kente used for the stilettos

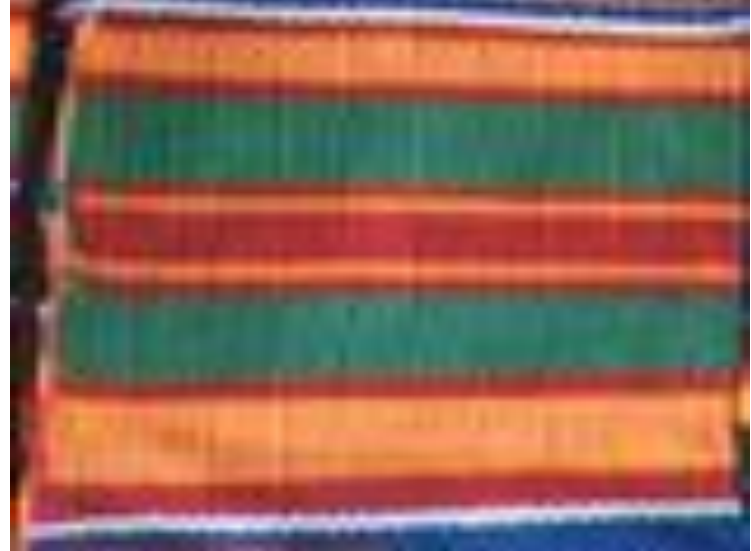

Fig 2:- Babadua kente in red, blue, yellow, green and white colours

(Kente Cloth.net, 2010)

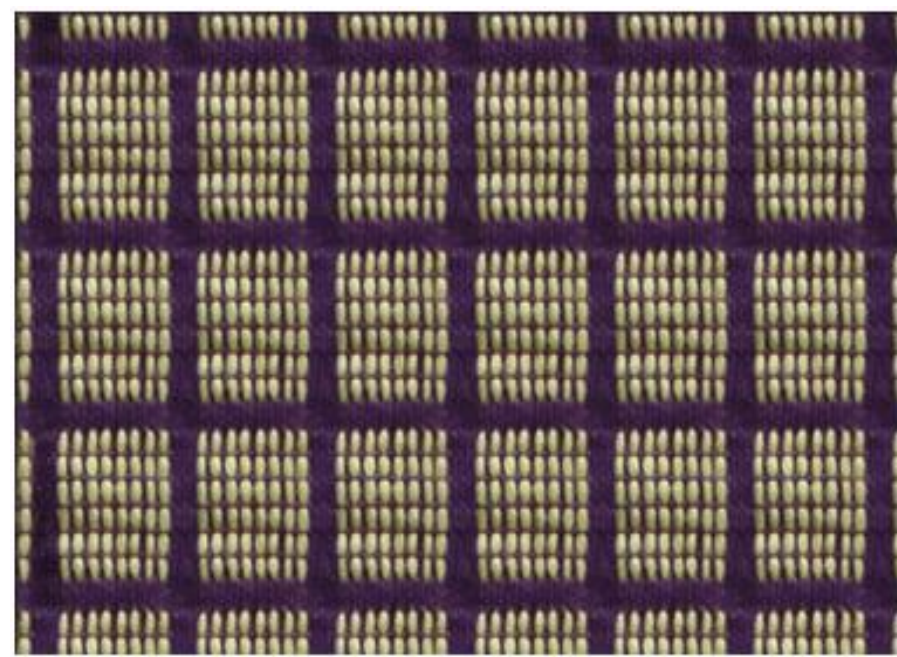

Fig 3: The edwini kente used for the stilettos

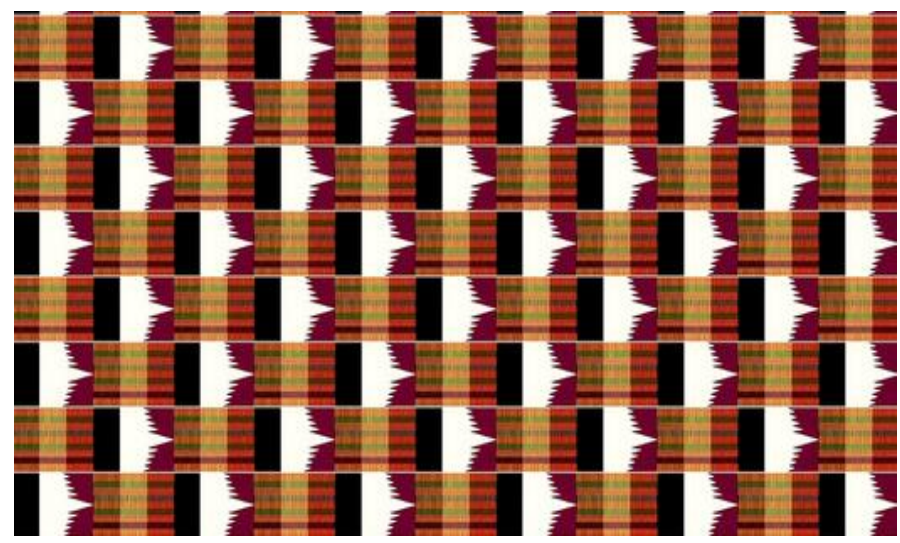

Fig 4: Awia repue (rising sun) kente design

(Heart of Afrika Designs, 2009) 


\section{B. Methodology}

\section{Research design and population}

The descriptive research method was used to give details on the tools and materials used for the footwear, types of beads and kente, and the processes for making the beaded kente ladies footwear for traditional weddings in Ghana. The participatory product design method (Sanders, 2002) was also used, where the would-be users of the footwear were involved in the design process. In this case, they were consulted for their views and comments right from the early design stages till actualisation of the product.

The target population (users of traditional footwear) for the study was 150 residents of Manhyia, a suburb of Kumasi. Of this, 100 people were contacted. Of the 100, 70 were female and 30 men. In terms of age, 18-25 year olds constituted 40 percent, 26-35 year olds constituted 35 percent and 36 year olds and above, 25 percent. The simple random sampling method was used and enabled the researchers to solicit the opinions of a wide range of users. Data was collected through interviews and questionnaire.

\section{$>$ Conceptualisation}

At the outset, the target price, target users and product features were established. The target price was seventy cedis ( $\varnothing 70.00)$; the target users was the youth, primarily between the ages of eighteen (18) and thirty-five (35) years; and product features as a pair of shoes that incorporates beads and kente, has high heel (4 inches long), has strength that aids its use, and has traditional philosophical backing. Upon these bases intended designs/sketches were made. The sketches captured the style and nature of the would-be shoe. In addition, the needed materials or supplies which included leather, rubber, wood, plastic, canvas, fabric, foams, metal, and other auxiliary materials were taking through appropriate processes and assembled.

\section{$>$ Production process: Stilettos}

This involved six (6) operations: pattern cutting, closing, lasting, attaching, arrangement of beads, and finishing. The manufacturing procedure drew inspiration from the processes espoused by wiseGEEK, 2013.

Patterns that would come together to form the shoe were cut. They consisted of the sole, the bottom part; the insole, the internal part that is placed directly under the foot; the outsole, the layer that directly touches the ground; the heel, the bottom back part (that was intentionally made high because it is stiletto); and the upper, the part that holds the shoe on the foot.

The second operation was closing. At this stage, every one of the aesthetic coverings of the shoe was brought together. It involved piercing, punching, wedging, ridging of the uppers (the kente supported with leather), placing it with lining and sewing them together.

Lasting was then done; the upper was stretched over the last. Some force was applied to stretch the upper on to the different points of the last. This made the upper acquire the shape of the last, which is the intended shape of the shoe. This study made use of an existing last (the structure over which the shoes were formed); of size 38 .

The upper and the sole were then put together via gluing with shoemakers glue (Type 99 Super Adhesive). This process is described simply as attaching by some shoemakers and was the fourth operation.

Needle and twine were then used to string the selected beads in a harmonious and colourful pattern that went along with the colours of the kente fabric. (Fig. 5).

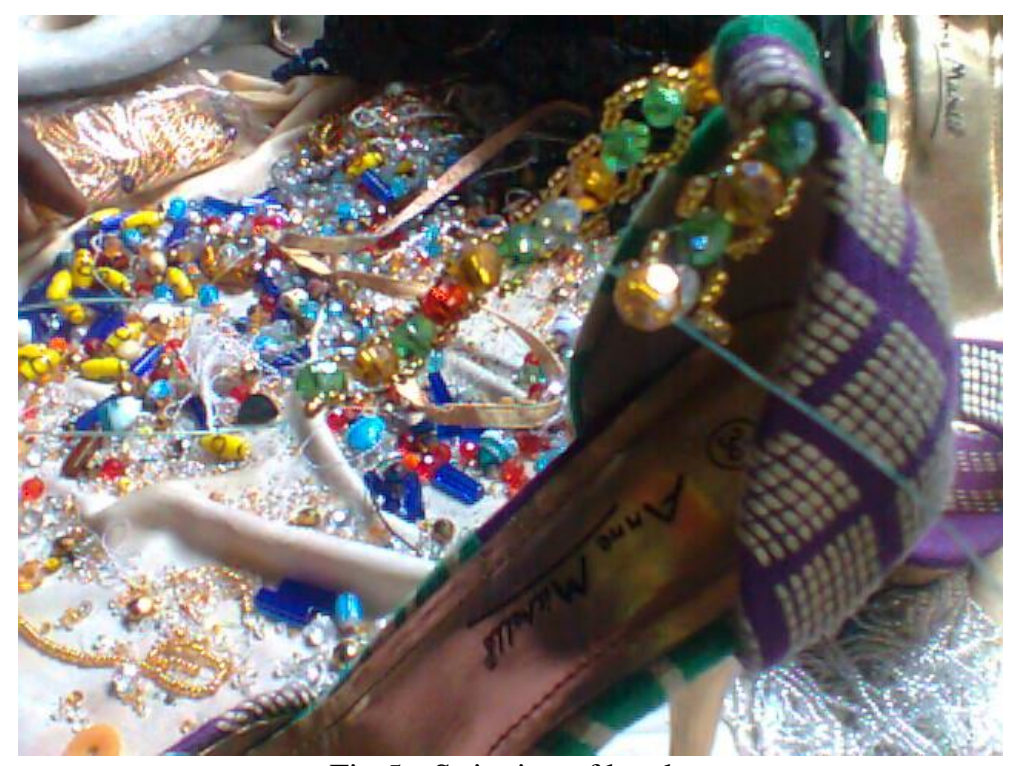

Fig 5:- Stringing of beads 
ISSN No:-2456-2165

At the finishing stage of production, cutting and trimming off of excess materials was done; as well, cleaning and polishing of the parts was done to make the shoe presentable. (Fig. 6). A metal clip with glass studs was fastened to the upper, of the shoe, to enhance its appearance.

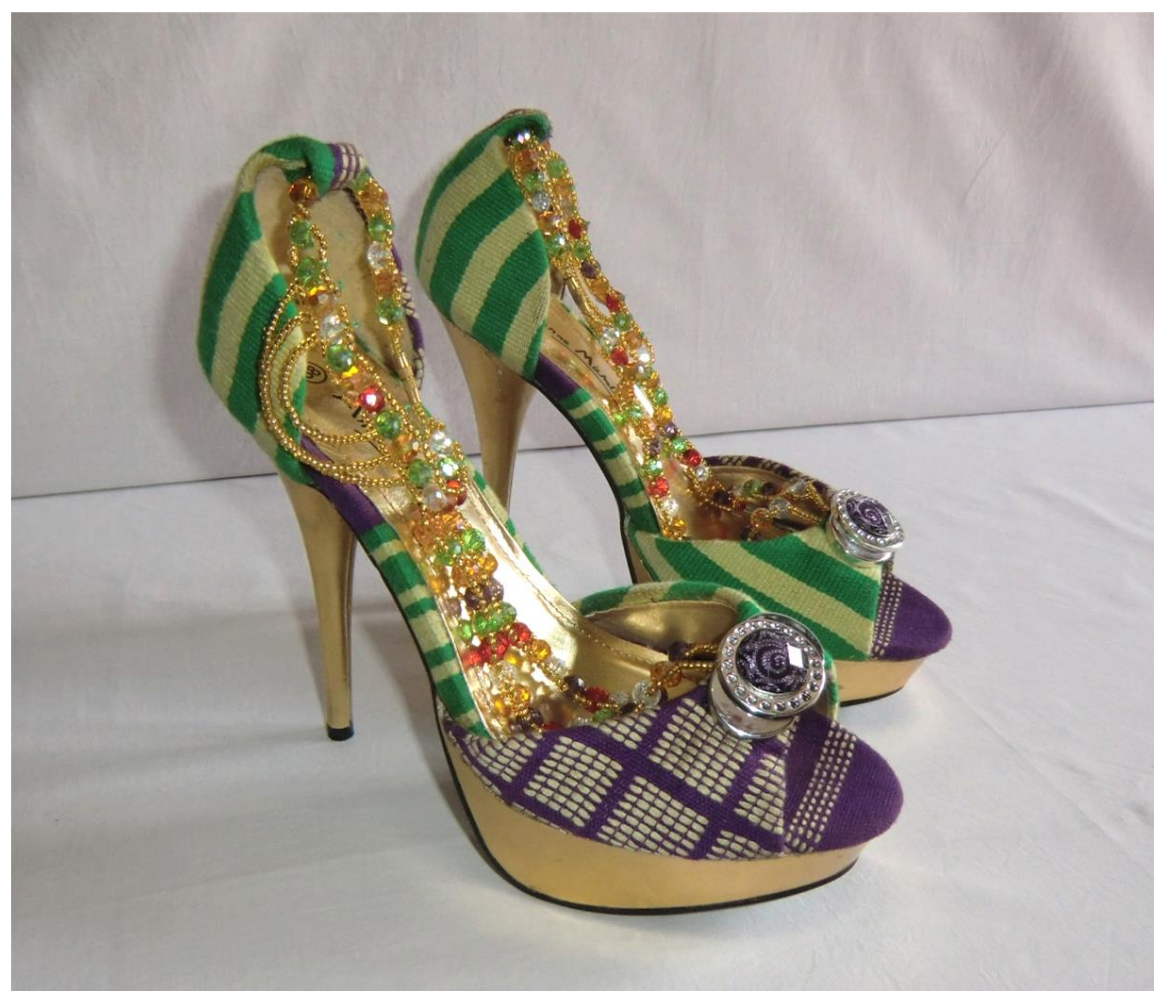

Fig 6:- Finished shoe

\section{Beading technique}

The beads were arranged with the ellipsoids ( $7 \mathrm{~mm} \times 9 \mathrm{~mm}$ in size) at central position whiles the small rounded ones ( $2 \mathrm{~mm} \mathrm{x}$ $2 \mathrm{~mm}$ in size) were placed on either side (of the said ellipsoids). Three small rounded beads were placed on either side to link two ellipsoid beads. The six beads together formed a link from one ellipsoid to another (Fig. 7). Different colours of the ellipsoid beads were used to spice the appearance of the stilettos (Fig. 8).

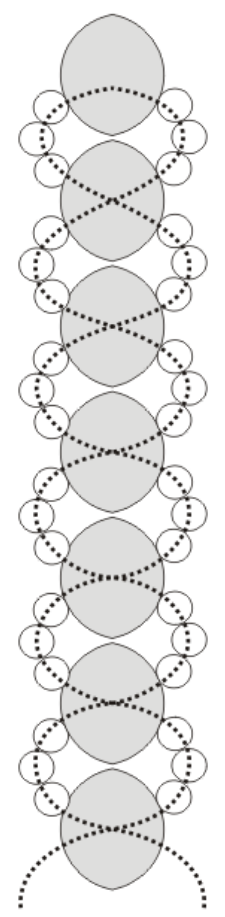

\section{KEY}

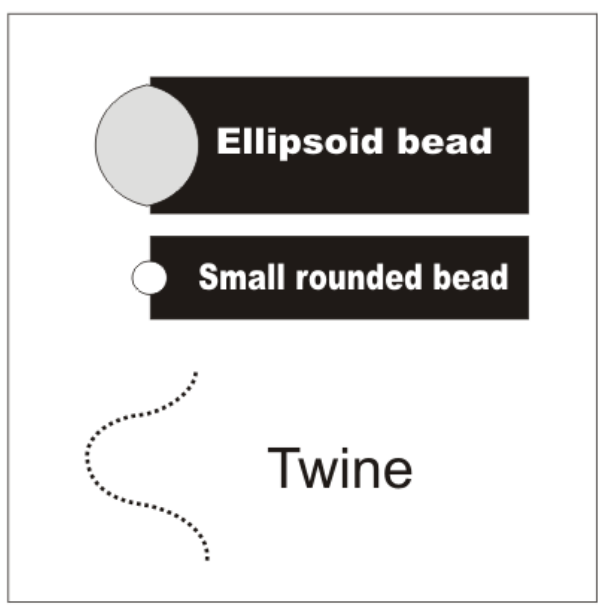

Fig 7:- Beading technique 
ISSN No:-2456-2165

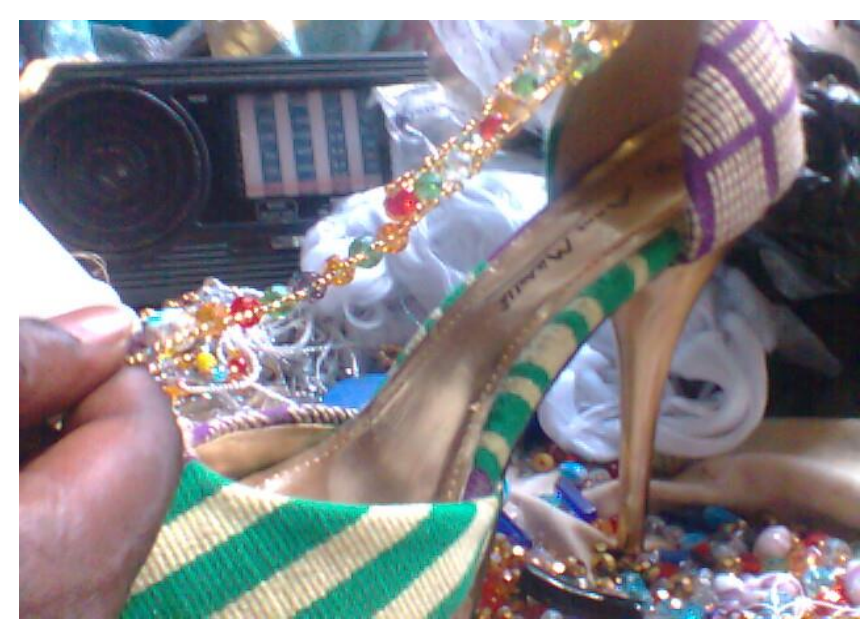

Fig 8:- Arrangement of beads

\section{RESULTS \& DISCUSSION}

\section{Examples of footwear used by brides for traditional weddings in Ghana}

Some of the footwear types used by brides for traditional weddings are the ahenema, stilettos, wedge, and flat shoes (Figs. 9, 10,11 , and 12, respectively). It was realised that westernisation had increased the taste for stilettos and flat shoes. However, with regards to ceremonies the stilettos is most rampant among other high heels. To this end, the stilettos type was selected for integration with beads and kente as a way of improving its design.

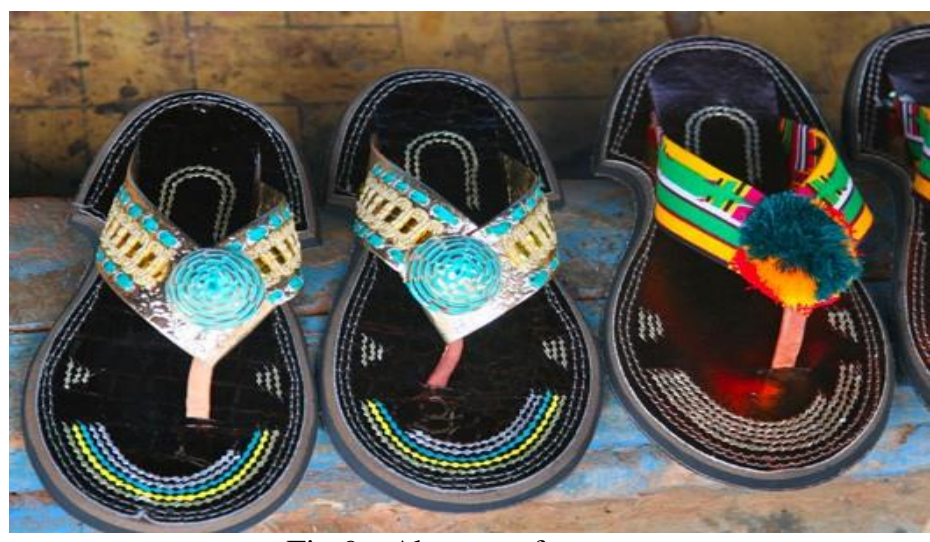

Fig 9:- Ahenema footwear

(Serra, 2012)

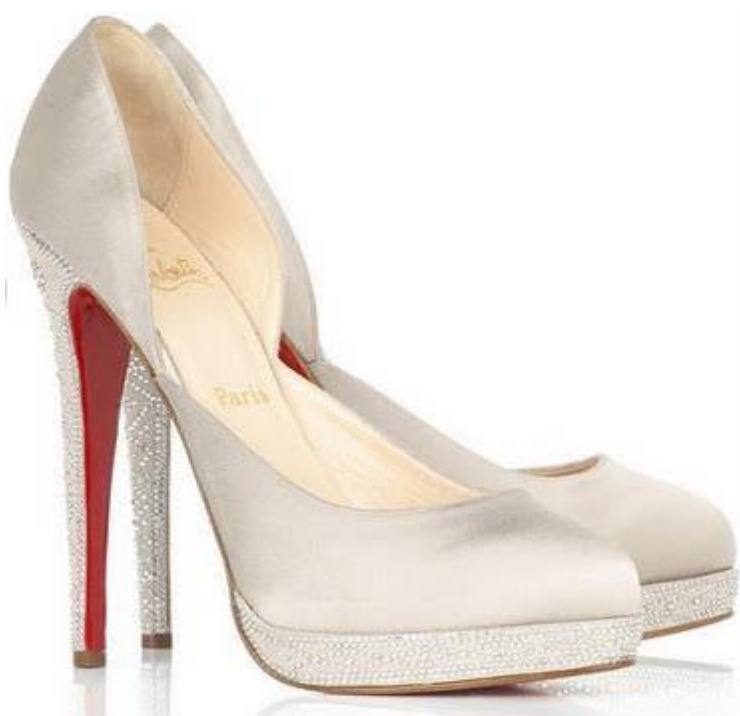

Fig 10:- Women's stilettos for weddings (Trend wedding shoes, 2009) 


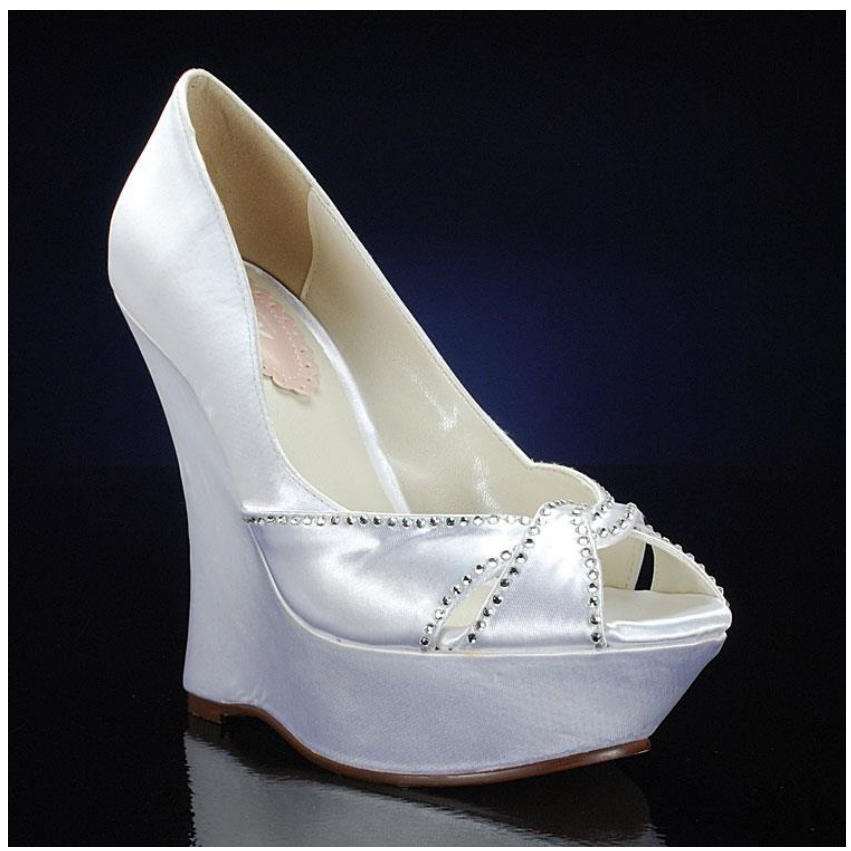

Fig 11:- Women's wedge shoe for weddings

(Bridalshoes, n.d.)

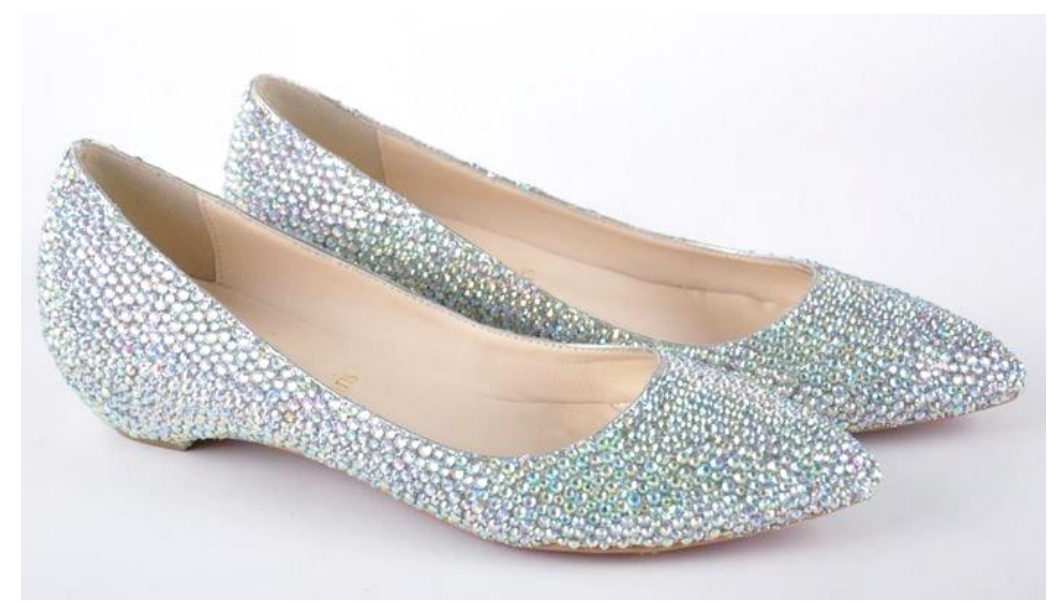

Fig 12:- Bedazzled flat shoes.

(Fox \& Jane, 2012).

Improved stilettos through the integration of beads and kente

\section{- Description}

The stiletto is of size 38 and has been designed to sell for seventy cedis ( $\varnothing 70.00)$ compared with most stilettos, on the market that sell between eighty (ф80.00) and hundred cedis $(\varnothing 100.00)$. The target users are the youth, mostly between the ages of eighteen (18) and thirty-five (35) years. The shoe incorporates the babadua and edwini kente designs, with glass beads, a locket (for holding the feet in the shoe), and a metal clip on the upper for aesthetic appeal. It has a high heel that has a height of four (4) inches. Overall, it is made up of the following colours: gold, green, red, silver, violet, white, and yellow. This is so because it must match with most wedding dresses and accessories used by brides in most Ghanaian traditional weddings.

\section{- Improved aspects}

The stiletto was improved at three levels: aesthetics, function, and philosophical backing. On aesthetics, the variety of interrelated colours are in line with the symbolic Ghanaian meanings such as wealth, royalty, gentleness, calmness, sweetness, tenderness, blood relationship, marital and spiritual feelings. This symbolic nature makes the stilettos culturally, socially and artistically appealing.

Concerning function, the product is made more comfortable by the kente lining (insole) which reduces perspiration of the foot and acts an anti-slip material for ergonomic purposes. This is so for the reason that the kente material increases aeration around the feet.

The philosophical connotations of the babadua and edwini kente such as strength, toughness, resiliency, power and superiority for the babadua (Kente Cloth.net, 2010), and ingenuity and creativity (Sabutey, 2009) for the edwini, 
speak a lot about the product and the user in the light of marriage. This means the marital union will be strong, tough, withstand all adversities, be a positive influence on society, and bring about newness of life between the couple and the environment. This newness of life is both physical and spiritual.

\section{- Trial of the product}

The general comment from the trial-testing was that the shoes are comfortable, aesthetically pleasing and satisfies the intended purpose (Figs. 13 and 14). However, the emphasis was on the aesthetics induced by the kente and the beads. They commented on its uniqueness, especially in the application of the beads.

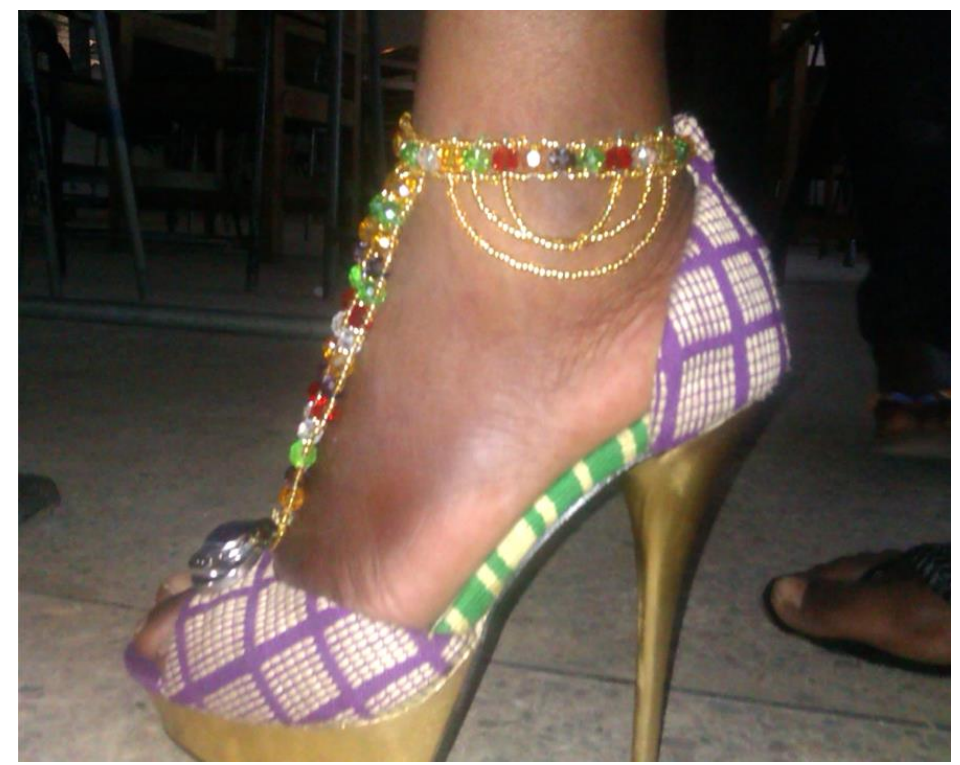

Fig 13: Trial of the finished shoe (outer view).

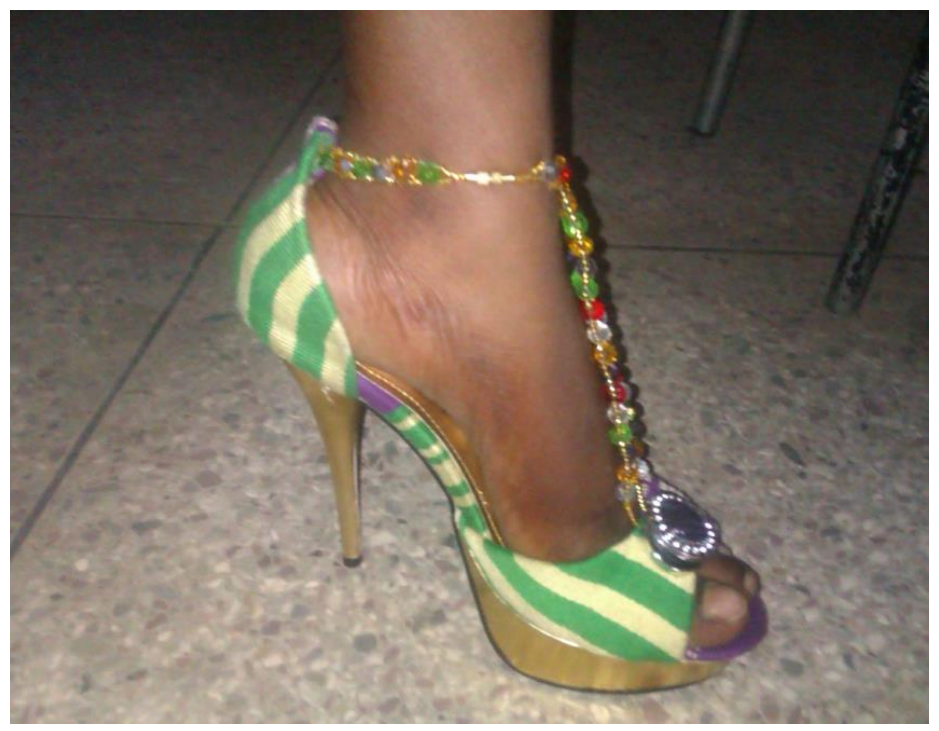

Fig 14: Trial of the finished shoe (inner view).

\section{CONCLUSION AND RECOMMENDATIONS}

This study explored the integration of beads and kente into the making of contemporary but traditional bridal footwear (stilettos) for Ghanaians. It was realised that the preference today's woman has is for flat or stiletto kind of shoe for traditional weddings. At the start (design stage), the target price, target audience and product features were established based on which intended designs/sketches were made. At the manufacturing stage, six (6) processes: pattern cutting, closing, lasting, attaching, arrangement of beads, and finishing were gone through to realize the shoe.
Techniques employed were user friendly and can be practiced by many a person. Non-governmental organizations (NGOs) and related governmental outfits that offer support to small and medium scale producers should re-strategize to make their services more accessible towards the rejuvenation of industries, for example, the Ghanaian footwear industry. This will go a long way to revitalize the sector, the Ghanaian economy and culture.

Last but not least, it is not feasible now for the Ghanaian manufacturer to compete with the western world in the manufacture of stilettos, so it is recommended that, 
as part of the importation of the shoes, its non assembled parts should also be imported and assembled in Ghana. This will give room for the incorporation of local materials and accessories to make them more culturally acceptable.

\section{ACKNOWLEDGEMENTS}

People of goodwill are difficult to find and should be duly acknowledged when they offer help. Warm appreciation goes to the following persons who helped with the research work: Alex Gyambrah Baah, Bridget Owusu Nsafoah, Christiana Yaa Miller, Edward Berchie Osei, Felix Appiah, Jacob Sarboah Danquah, Linda Addae-Badu, Natasha Bentumba Owusu and Pepertual Oppong Peprah. Sincere thanks go to you all.

\section{REFERENCES}

[1]. AsanteMan Kente Works (2013). History of kente. Retrieved June 12, 2013 from http://www.asantemankente.com/native.shtml

[2]. Ashe, J. (2012). Progression of aesthetic: a study of beads and adornment in contemporary Krobo society. Independent Study Project (ISP) Collection. Paper 1248. Retrieved June 12, 2013 from http://digitalcollections.sit.edu/isp_collection/1248

[3]. Bridal Shoes.com (n.d.). Cherish by pink. Retrieved June 13, 2013 from http://www.bridalshoes.com/cherish\#.Ubm7v_nwkfU

[4]. Fox \& Jane (2012). 5 Comfy flats to wear in your big day: Bedazzled flat shoes. Retrieved July 9, 2013 from http://www.rainbowclub.co.uk/blog/flatwedding-shoes

[5]. GhanaNation portal (2010). Marriage in Ghana. Retrieved June 12, 2013 from http://content.ghananation.com/articles/Marriage-inGhana.aspx

[6]. Heart of Afrika Designs (2009). Awia Repue (Rising Sun) Kente Design. Retrieved July 11, 2013, from http://www.artbreak.com/work/show/508855-awiarepue-rising-sun-kente-design-avmobley

[7]. Kente Cloth.net. (2010). Kente Cloth Weave Patterns \& Meaning: Babadua. Retrieved July 11, 2013, from http://www.kentecloth.net/kente-cloth-designs-andmeanings/

[8]. Sabutey, G. T. (2009). Aesthetics, Appreciation and Criticism among Indigenous Asante kente Weavers: Implications for Art Education and National Development. Unpublished Dissertation, Kwame Nkrumah University of Science and Technology, Kumasi.

[9]. Sanders, E. B. (2002). From user-centered to participatory design approaches (pp. 1-8): Taylor \& Francis. Retrieved February 2011 from http://www.mendeley.com/research/usercenteredparticipatory-design-approaches/\#

[10]. Serra, E. V. (2012). Ahenemaa sandals. Retrieved June 13, 2013 from http://www.elia.ws/blog/2009/10/

[11]. TheFreeDictionary (2013).Bead. Retrieved June 12, 2013 from http://www.thefreedictionary.com/bead
[12]. Travel Africa Magazine. (1999). Culture: the language of beads. Travel Africa Magazine, 114. Retrieved July 9, 2013 from

[13]. http://www.travelafricamag.com/index 2.php?option=c om_content\&do_pdf $=1 \& i d=156$

[14]. Trend Wedding Shoes (2009). Wedding shoes photo gallery. Retrieved June 13, 2013 from http://weddingshoes2009.blogspot.com/2009/09/trend -wedding-shoe-with-stilettos-heel.html

[15]. wiseGEEK (2013). How are shoes made? Retrieved June 13, 2013 from http://www.wisegeek.org/howare-shoes-made.htm 